\title{
ERRATUM
}

\section{NUMBERICAL STUDY OF JASTROW-SLATER \\ TRIAL STATES FOR THE FRACTIONAL QUANTUM HALL EFFECT}

\author{
N. Trivedi and J. K. Jain \\ [MOD. PHY. LETT. B, Vol. 5, No. 7 (1991) 503-510]
}

\begin{abstract}
On page 509
Under acknowledgements, line 3 should read
\end{abstract}

DMR-88-14311... 